Journal of Extension Education

Vol. 29 No. 3, 2017

DOI:https://doi.org/10.26725/JEE.2017.3.29.5910-5916

\title{
Kisan Call Centre Services to the Farming Community: An Analysis
}

\section{S. Kavitha ${ }^{1}$ and N. Anandaraja ${ }^{2}$}

\begin{abstract}
Kisan Call Centre (KCC) is one of the major initiatives taken up by the Ministry of Agriculture and Farmers Welfare, Government of India to provide timely agriculture and allied sector information to the farming community through landline or mobile connection. The service is provided through a toll-free number of 1800-180-1551. Considering the importance of $\mathrm{KCC}$, the research study was conducted in Mahaboobnagar District of Telangana State in India with a sample size of 90 farmers to find out and analyze benefits obtained by the farming community through Kisan Call Centre Services. The results revealed that maximum number of the respondents expressed that KCC advisory was able to save cost of cultivation and in forecasting the pest and disease outbreak in a particular region. The study also showed that farming experience, source of irrigation, contact with extension agencies, participation in extension methods, perception towards mobile phones in farming and innovativeness showed positive and significant relationship with the benefits obtained by respondents.
\end{abstract}

Keywords : Kisan Call Centre; Advisory, Benefits; Telangana

\section{INTRODUCTION}

Agricultural extension and farmeroutreach programmes are facing major challenges in terms of cost-effective outreach, solutions tailored to needs of individual farmers and an image that is farmer-friendly (Ramamritham, 2006). The mobile technologies have created new channels to communicate with others. The final produce should provide better marketable price to farmers, where the market intelligence is the key, which provides regular information about nearby markets in local language.

The scheme Kisan (Farmer) Call Centres (KCC) was launched by the Ministry of Agriculture and Farmers Welfare, Government of India, on 21st

1. Ph. D. Scholar, Department of Agricultural Extension, Professor Jayashankar Telangana State Agricultural University (PJTSAU), Rajendranagar, Hyderabad-500 030 and 2.Assistant Professor (Agrl. Extension), Agricultural College and Research Institute, Kudumiyanmalai, Pudukkottai-622104. 
January 2004. The Farmer Call Centre is a synthesis of two hitherto separate technologies namely, the Information and Communication Technology (ICT) and the Agricultural Technology both having specialized domains. A toll-free telephone number "1800-180-1551" has been provided that is operational on all days from 6.00 am to $10.00 \mathrm{pm}$. Beyond these hours the calls are attended in the Interactive Voice Response System (IVRS) mode.

A Kisan Call Center is expected to bridge the information gap between the expert agriculturists and farmers. Replies to the farmers' queries are given in 22 local languages. The present study was undertaken with the objective to enlist the benefits obtained through Kisan Call Centre and to find out the relationship between different independent variables and the benefits obtained by the farmers.

\section{METHODOLOGY}

Expost facto research design was followed for the study, which was conducted in Mahaboobnagar District of Telangana State. This district has the highest net sown area under main crops among all the districts in Telangana (Season and Crop Report 2012-13). In addition, this district had registered highest KCC services as per the dashboard data of m-Kisan portal (mkisan.gov.in)

The Mahaboobnagar district has been divided into 64 mandals (blocks). Out of the 64 mandals, two mandals namely Manopad and Gattu were selected since they have maximum area under cultivation of crops. Three villages from each block were selected at random. All togehter six villages in two blocks were chosen for the study. From each village, 15 beneficiary farmers were selected for the study with a total sample size of 90 respondents which was felt adequate. Simple random sampling method was followed while selecting the farmers. Data were collected by using wellstructured interview schedule with pretesting procedure. Percentage analysis and correlation technique was performed to interpret data.

\section{FINDINGS AND DISCUSSION}

\section{Benefits of KCC to the Farming Community}

Farmers are availing many benefits out of KCC services. The benefits are classified into Technological, Economic, Communication and Other benefits. The distribution of beneficiary respondents according to benefits obtained through $\mathrm{KCC}$ is given in Table 1 . 
Table 1.

Distribution of Respondents according to Benefits

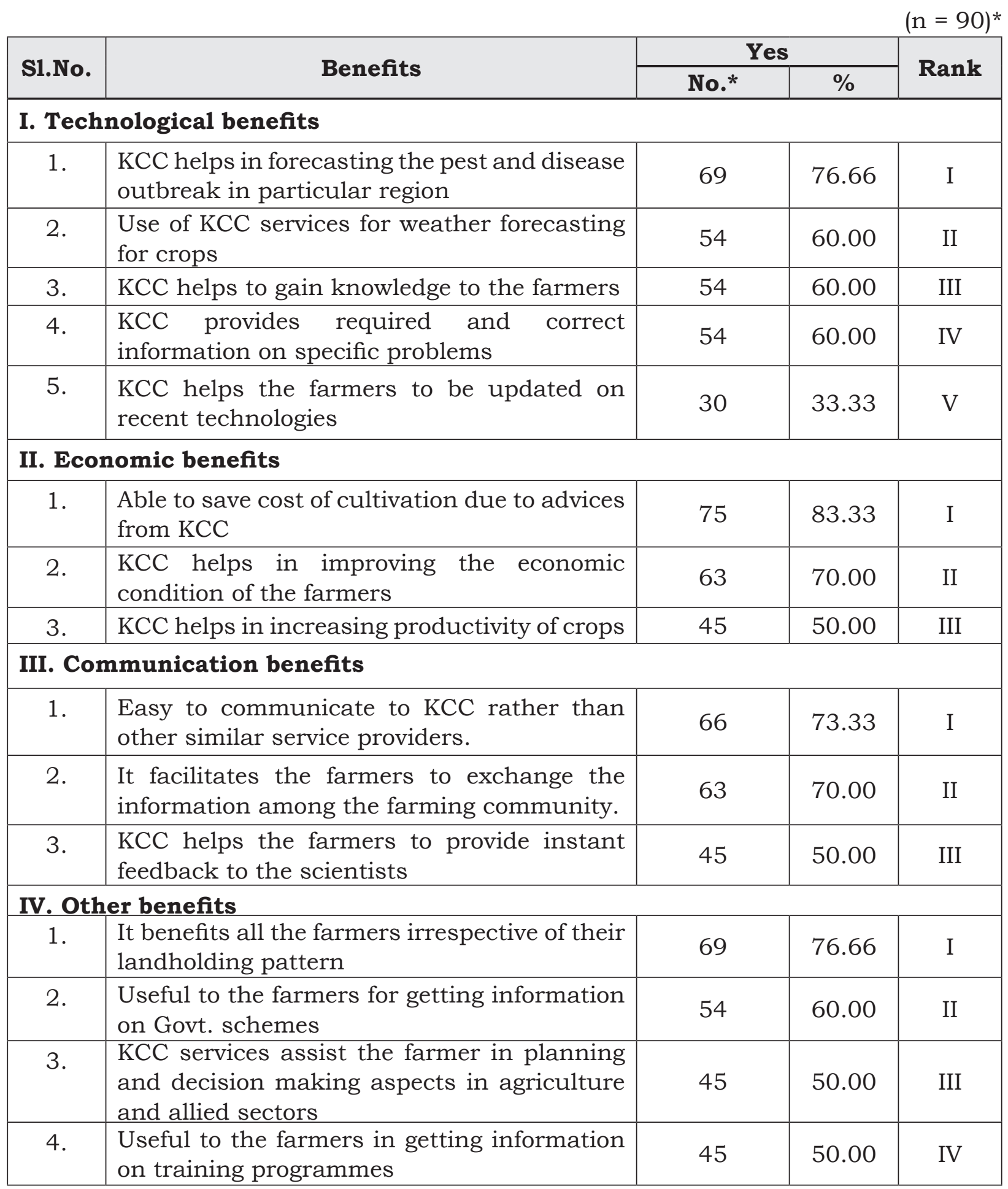

*Multiple responses obtained 


\section{Technological benefits}

It could be inferred from Table 1 that the forecast on the pest and disease outbreak in a particular region ranked first (76.66\%) among the services through $\mathrm{KCC}$ because pest and disease incidence was more as the farmers are growing multiple crops.

The second benefit availed by the farmers was the usage of KCC services for weather forecasting for crops (60.00\%). The reason may be that weather plays a crucial role in all farming activities. The farmers might have preplanned their farm activities according to weather conditions.

KCC helps the farmers to gain knowledge $(60.00 \%)$ by explaining technical advisories in a proper and understandable manner. In order to increase their income, the $\mathrm{KCC}$ service would have aroused their interest to acquire more knowledge. Further, the agricultural scientists and Level-I officials (Koshy \& Kishore Kumar, 2016), also played a significant role in providing information to the farmers through mobile and landline telephone connectivity.

Since Level-I officials are agrigraduates with experience in practical knowledge sharing through KCC, significant number of farmers $(60.00 \%)$ benefited to avail exact information on specific problems. Besides, KCC helps the farmers to be updated on recent technologies (33.33\%) through monthly training programmes conducted by the nodal agency to the KCC officials.

\section{Economic benefits}

Economic benefits gained by farmers on using KCC in the order of their importance were saving cost of cultivation due to advice from $\mathrm{KCC}$, improving the overall economic condition of the farmers and increasing productivity of crops. The kind of advisories provided by the KCC operators to farmers is timely without any time lag. The solutions offered by the operators are pragmatic and easy to adopt at the field level.

\section{Communication benefits}

The list of communication benefits perceived by the farmers are, easy communicate with KCC rather than other similar service providers, KCC facilitating the farmers to exchange information among the farming community and helping the farmers to provide instant feedback to the scientists. As the $\mathrm{KCC}$ service provider receives the phone call in local language, he/she tries to understand the farmer's issues in a clear manner and offers technological advice immediately which helps the farmer to save the crop from pest and diseases.

\section{Other benefits}

Other benefits obtained by the farmers were KCC provides services to all 
farmers irrespective of their landholding pattern $(76.66 \%)$ followed by helpful to the farmers for getting information on Govt. schemes $(60.00 \%)$, KCC services assist the farmers in planning and decision making aspects in agriculture and allied sectors $(50.00 \%)$ and is useful to the farmers for getting information on training programs $(50.00 \%)$.

\section{Overall benefits}

Based on the data of technological, economical, communication and other benefits, overall benefits were calculated. The beneficiary respondents are classified into low, medium and high category according to benefits obtained through KCC and given in table 2 .

Table 2.

Distribution of Respondents according to Overall Benefits

$(\mathrm{n}=90)$

\begin{tabular}{|c|l|c|c|}
\hline \multirow{2}{*}{ S1.No. } & \multirow{2}{*}{ Overall benefits Categories } & \multicolumn{2}{|c|}{ Beneficiaries } \\
\cline { 3 - 4 } & & No. & Per cent \\
\hline 1. & Low & 22 & 24.44 \\
\hline 2. & Medium & 54 & 60.00 \\
\hline 3. & High & 14 & 15.56 \\
\hline & Total & 90 & 100.00 \\
\hline
\end{tabular}

The data presented in Table 2 , shows that $60 \%$ of the respondents had expressed medium level of benefits, followed by low and the rest of the respondents obtained high level of benefits through KCC. It could be concluded from the results that two thirds of the beneficiaries had benefited through call centre. The possible reason for that is $\mathrm{KCC}$ is providing services to farmers free of cost. Further, the farmers may make calls any number of times in the prescribed hours and they could get the solutions to farm problems.

Correlation Analysis of Socio-economic profile with Benefits

Correlation analysis was carried out between the Independent Variables and benefits and the results are presented in Table 3. 
Table 3.

Correlation of Independent Variables with Benefits

$(\mathrm{n}=90)$

\begin{tabular}{|c|l|c|}
\hline S1. No. & \multicolumn{1}{|c|}{ Independent Variables } & r value \\
\hline 1. & Age & $-0.092 \mathrm{NS}$ \\
\hline 2. & Educational Status & $0.017 \mathrm{NS}$ \\
\hline 3. & Farm Size & $-0.226^{*}$ \\
\hline 4. & Farming Experience & $0.309^{* *}$ \\
\hline 5. & Cropping pattern & $0.008 \mathrm{NS}$ \\
\hline 6. & Source of irrigation & $0.210^{*}$ \\
\hline 7. & Material Possession & $-0.392^{* *}$ \\
\hline 8. & Contact with Extension and other Agencies & $0.317^{* *}$ \\
\hline 9. & Information seeking behavior & $0.095 \mathrm{NS}$ \\
\hline 10. & Participation in Extension Methods & $0.236^{*}$ \\
\hline 11. & Perception towards mobile phone in farming & $0.376^{* *}$ \\
\hline 12. & Innovativeness & $0.270^{* *}$ \\
\hline
\end{tabular}

**Significant at 0.01 level of probability

* Significant at 0.05 level of probability NS $=$ Non-Significant

The data in Table 3 shows that six variables out of twelve variables such as farming experience, source of irrigation, contact with extension and other agencies, participation in extension methods, perception towards mobile phone in farming and innovativeness showed positive cum significant relationship with the benefit level of respondents.

It could be seen from the results that out of twelve variables taken for the study, four variables namely farming experience, perception towards mobile phone in farming, innovativeness exhibited significant and positive correlation with benefits at one per cent level of significance. Source of irrigation, contact with extension and other agencies, participation in extension methods showed positive cum significant association with benefits at five per cent level of significance. Whereas, material possession showed negative and significant association with level of benefits at one per cent level of significance and farm size showed negative and significant association with level of benefits at five per cent level of significance. 
Helpline services such as KCC provide valuables information to the farmers free of cost. Hence, perception towards mobile phone, in farming could have showed positive and significant relationship with level of benefits.

Innovative farmers rely on modern technologies. By using services like KCC and adopting modern technologies, farmers can get more profits, Hence, innovativeness might have showed positive and significant relationship with benefits.

\section{CONCLUSION}

The $\mathrm{KCC}$ is a unique free service provided by the Department of Agriculture and Cooperation Govt of India throughout India. $\mathrm{KCC}$ is at present providing free SMS services to as well the enrolled farmers in English and regional languages.

The results show that the benefits accrued upon using KCC are significant. Therefore awareness on this useful service need to be spread among the farming community.

\section{REFERENCES}

Koshy, S. \& Kishore Kumar, N. (2016). Attitude of Farmers towards Kisan Call Centre, Journal of Extension Education, 28(4) doi: https://doi.org/ 10.26725/JEE.2016.4.28.5753-5759

Ramamritham, K. (2006), Innovative ICT tools for information provisioning via agricultural extensions, 1st IEEE/ACM International Conference proceedings on ICT4D, Berkeley. 